\title{
Selection of Research Paradigms in English Language Teaching: Personal Reflections and Future Directions \\ Thi Thuy Loan Nguyen
}

Department of English, Faculty of Education and Educational Innovation Kalasin University, Thailand

\section{Abstract}

Learning and teaching English in the age of globalization, digitalization and diversifications has constantly challenged our current understanding about the learners. In order to maximize the effectiveness of education, we need to continuously innovate our curriculum, pedagogy, assessments and evaluation. Research has helped this continuous innovation by providing key insights about students and teachers' demands and needs and then shaping the strategies, policies and innovations in education. This paper attempts to explain this phenomenon from my perspective. First,

Corresponding Author: Thi Thuy Loan Nguyen thuyloancailay@gmail.com

Received: 1 July 2019

Accepted: 18 July 2019

Published: 31 July 2019

Publishing services provided by Knowledge E

(c) Thi Thuy Loan Nguyen. This article is distributed under the terms of the Creative Commons Attribution License, which permits unrestricted use and redistribution provided that the original author and source are credited.

Selection and Peer-review under the responsibility of the AICLL 2019 Conference Committee. I will provide a brief review of research paradigms and dominant research paradigms in English Language Teaching (ELT), followed by my personal reflections on what research approaches I followed, why I selected them and what procedures I followed. The discussion on my selected approaches and what I learned from my research will also be shared together with my opinion on the possible directions for future research in ELT.

Keywords: research paradigms; mixed methods; methodologies; English Language Teaching; multilingual writers, pre-service teachers

\section{Research Paradigm Overview}

\subsection{Definitions and significance}

The concept of research paradigms has been puzzling to articulate and challenging to apply for many graduate students and novice researchers. According to Kivunja and Kuyini (2017), this confusion stems from the diversity in how this term is employed in both daily and research discourses. In daily use, the term "paradigm" does not include its integral qualities (i.e., epistemology, ontology, methodology or axiology), and there is a considerably overlapping extent of its definitions and explanations among leading researchers in various research contexts and academic disciplines (Creswell, 2007; Guba \& Lincoln, 2005; Johnson, 2011). Originated from Greek language, "paradigm” was first used to mean a philosophical way of thinking (Kuhn, 1962), and in scientific research 
this term is used to describe a researcher's worldview, perspective, thinking or set of shared beliefs that inform the meaning or interpretation of research data (Mackenzie \& Knipe, 2006; Schwandt, 2001). In this definition, a paradigm reflects the shared assumptions and principles that frame how a researcher sees the world, interprets and acts within that world. Through this conceptual lens, the researcher examines the methodological aspects of their research project to determine the research methods that will be used, and how the data will be analyzed.

Similarly, Denzin and Lincoln (2000), leaders in qualitative research, describe paradigms as human constructions, the process in which researchers make meaning of their data through their personal experiences of the real life informed by their interactions with participants. In social sciences, in which the combination of quantitative methods (such as surveys and questionnaires) and qualitative methods (such as interviews and ethnographical studies) is commonly employed, a paradigm is viewed as both "worldviews", reflecting researchers' assumptions about reality, methodology and epistemology (Creswell \& Plano, 2011; Guba \& Lincoln, 2005) and "exemplars" or an intellectual framework shared within a scientific community (Ghiara, 2019, p. 2; Maxwell, 2016; Morgan, 2007). Paradigms are thus important as they provide scholars in a particular discipline with beliefs and dictates, which affect what should be studied, how it should be studied, and how the research results should be interpreted. In other words, the paradigm has significant implications for every decision made in the research process, including choice of methodology and methods and how meaning will be constructed from the data researchers will collect (Willis, 2007).

\subsection{Essential elements of a research paradigm}

Each paradigm comprises four elements covering its basic assumptions, beliefs, norms and values, namely ontology, epistemology, axiology and methodology (Lincoln \& Guba, 1985; Patton, 2002). Ontology is concerned with the assumptions researchers make in order to conceptualize the form and nature of reality, and what they believe can be known about that reality (Scotland, 2012). These assumptions, concepts or propositions help to orientate their thinking about the research problem, its significance, and how they might approach it in order to contribute to the existing knowledge. Ontology is so crucial to a paradigm because it seeks to determine the real nature or the foundational concepts which constitute themes that researchers analyze to make sense of the meaning embedded in the research data (Scott \& Usher, 2004). Epistemology refers to 
how we know the truth or reality. It focuses on the nature of human knowledge and comprehension that researchers can possibly acquire so as to be able to extend, broaden and deepen understanding in their research field. To understand the epistemological element of our paradigm, we should ask the very important question of "how we know what we know". Epistemology is important because it helps researchers to establish the faith they put in their data, and it affects how they will go about uncovering knowledge in a research setting. Axiology refers to the ethical issues that need considering when planning a research proposal. As stated by Kivunja and Kuyini (2017), axiology involves defining, evaluating and understanding concepts of right and wrong behavior relating to the research. Together, these three paradigmatic aspects (ontology, epistemology and axiology) help to determine the assumptions and beliefs that frame researchers' view of a research problem, how they go about investigating it, and the methods they use to answer the research questions (known as methodology). In other words, from its philosophical assumptions about the nature of social reality (ontology), ways of knowing (epistemology), and ethics and value systems (axiology), a paradigm leads researchers into research question(s), selection of participants, instruments and data collection procedures as well as data analysis.

To sum up, because each paradigm is held by specific assumptions, choice of a paradigm for a research implies that the research will be nested in a particular epistemology, ontology and axiology. Hence it is the researchers' choice to determine their own paradigmatic view and how that informs their research design to best answer the question under investigation. In fact, how they select the most appropriate paradigm for their research topic depends on how they view the truth, what they know and how they know it, along with their theoretical perspective(s) about the research topic, the literature that exists on the subjects and their own value system (Figure 1). The philosophical beliefs about the nature of reality, knowledge and values, and the theoretical framework that informs comprehension, interpretation, choice of literature and research practice on a given topic of study will then guide the methodology which summarizes the research process (Figure 2).

\section{Dominant Research Paradigms Applied in ELT Research}

There are several major paradigms for educators and researchers to select for their inquiries into the policies and practices of English language education. Each paradigm carries related theories of teaching and learning, curriculum and assessment, professional development and so on. As reported in an examination of 1055 empirical research 


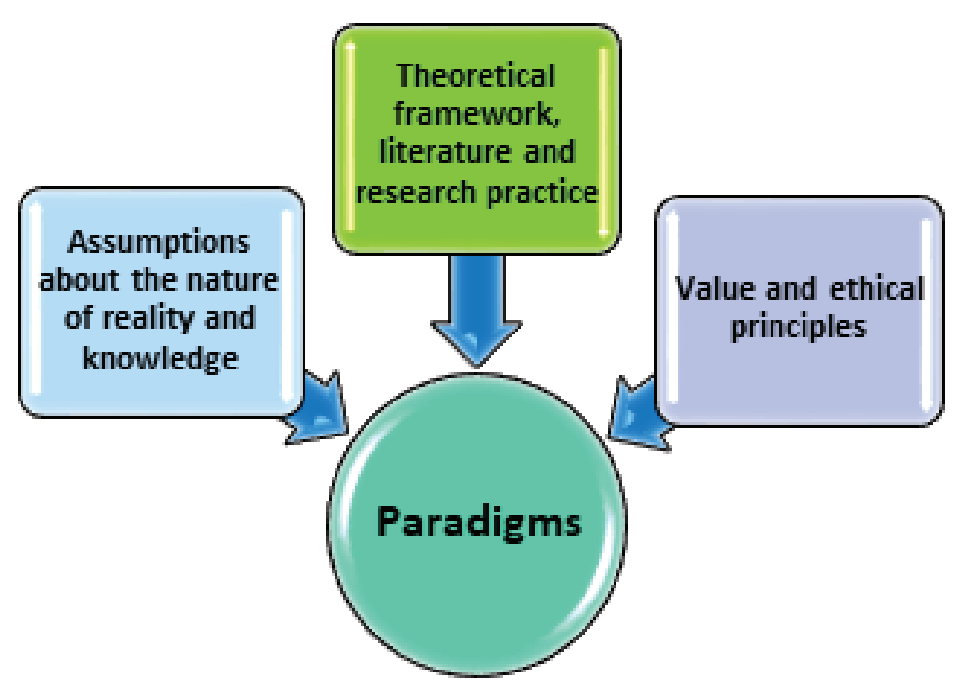

Figure 1: Factors influencing the choice of a paradigm.

\section{Assumptions about the nature of reality and knowledge}

\section{Value and ethical principles}

Figure 2: Methodology as convergence of three parts.

articles published from 2010 to 2016 in two reputable teacher educations journals by Crawford and Tan (2019), 46.5\% of the studies used qualitative methods, $27.9 \%$ used quantitative methods, and $25.6 \%$ used mixed methods. Within the proportion of mixed methods studies, a balanced qualitative and quantitative approach accounted for $71.1 \%$. Within the scope of this paper, only three prominent research paradigms with their characteristics and methodologies commonly referred to as quantitative, qualitative and mixed methods approaches will thus be briefly reviewed. 
TABLE 1: Summary of research paradigms in ELT (adapted from Kivunja \& Kuyini, 20017, pp. 30-36).

\begin{tabular}{|l|c|c|c|c|}
\hline Paradigm & Ontology & Epistemology & Axiology & Methodology \\
\hline Positivism & naive realist & objectivist & beneficent & experimental \\
\hline Interpretivism & relativist & subjectivist & balanced & naturalist \\
\hline Pragmatism & $\begin{array}{c}\text { non-singular } \\
\text { reality }\end{array}$ & relational & value-laden & mixed methods \\
\hline
\end{tabular}

\subsection{Positivist paradigm}

As seen in Table 1, the Positivist paradigm assumes naive realist ontology, a belief that there is a single truth or reality which remains stable and can be measured (objectivist epistemology), and human understanding is gained through a process of experimentation to test hypotheses, provide explanations, make predictions or search for cause and effect relationships of variables (Fadhel, 2002; Searle, 2015). The research conducted under the Positivist paradigm thus often employs experimental, quasi-experimental, correlational, causal comparative and survey methodologies (experimental methodology). In this paradigm, context is not important, and the research purpose is to find laws or law-like generalizations, which elucidate observable human behavior. Positivism is thus called Scientific Method, Empirical Science and Quantitative Research (Guba \& Lincoln, 2005). According to Mertens (2015), the beneficent axiology refers to the requirement that all research should maximize good outcomes and avoid or minimize any risk and harm that could occur during the research.

However, due to the fact that the social world where humans are involved is not value-free, and that it is not always possible to provide explanations of a causal nature, a derivative of this paradigm, known as the Post-positivist paradigm, is formed. This new paradigm accepts that reality is not absolute but probable, and it can never be fully understood. That means post-positivists acknowledge the influence of the researcher's theories, background, knowledge and values on what is observed. As stated by previous researchers (Creswell, 2008; Ghiara, 2019; Kivunja \& Kuyini, 2017; Taylor \& Medina, 2013), the Post-positivist paradigm is the modified scientific method for the social sciences, to which ELT belongs.

\subsection{Interpretivist paradigm}

The assumption of a relativist ontology means that there is no single reality or truth, and reality is explored, created or reconstructed through human interactions between the researcher and the research subjects and among the research participants (Chalmers, 
Manley, \& Wasserman, 2005). A subjectivist epistemology means that reality needs to be interpreted. That is the researcher makes meaning of their data through their own thinking and cognitive processing of data informed by their interactions with participants. In holding a naturalist methodology, the researcher uses data collected through interviews, discourses, text messages and reflective sessions, with the researcher acting as a participant observer. The frequent research methods utilized in the Interpretivist/Constructivist paradigm are case study, action research, grounded theory, ethnography, phenomenology, hermeneutics, phenomenography, heuristic inquiry, naturalist, narrative inquiry and discourse analysis. This paradigm is also called Constructivism, Social Constructivism or Qualitative Research paradigm (Guba \& Lincoln, 2005). A balanced axiology believes that the values of the researcher will be reflected in the balanced reports of the research findings.

Applied to ELT research, this paradigm enables researchers to build rich local understandings of the life experiences of teachers and students and of the cultures of classrooms, schools and the communities where they serve. Moreover, the interpretive inquiry engages teachers as reflective practitioners in developing enhanced understanding of the life-worlds of their students within their social, political, historic and economic settings (Taylor \& Medina, 2013). Common themes which have been the focus of this research paradigm since $\mathbf{2 0 0 0}$ are approaches to teaching, identity and socialization, narratives/lives and other developments like teacher beliefs, learner strategies and teacher reflection and learning (Richards, 2009).

\subsection{Pragmatic paradigm}

As stated by Kivunja and Kuyini (2017), this paradigm emerged from the argument among philosophers that a mono-paradigmatic orientation of research by employing a single scientific method was not sufficient to either access the truth about the real world by the Positivist paradigm or determine social reality under the Interpretivist paradigm. A worldview providing the most practical, appropriate and pluralistic research methods for studying the phenomenon at hand is thus needed (Patton, 2002). This has given rise to a paradigm that employs mixed methods as a pragmatic way (Pragmatic paradigm) to understand participants' actual behaviors, their beliefs behind the behaviors and the consequences that are likely to follow from their different behaviors. Different from the Mixed Methods which emphasize the "how to" aspects of research; however, Pragmatism places more importance on "why to do research" in a given way (Morgan, 2014). In other words, Pragmatism concentrates on beliefs that are more directly connected to 
actions. As seen in Table 1, this paradigm advocates a non-singular reality ontology (i.e., there is no single reality, and reality is constantly renegotiated, debated, interpreted in light of its usefulness in new unpredictable situations), a relational epistemology (i.e., relationships in research are best determined by what the researcher feels appropriate to that particular study), a mixed methods methodology (i.e., a combination of quantitative and qualitative research methods and design-based research), and a value-laden axiology (conducting research that benefits people).

\section{Reflections on My Selection of Research Paradigms}

\subsection{Who I am?}

A brief introduction about my background, I believe, will help the audience to better understand my reflections on selecting research approaches, as my experiences span from teaching primary kids and university students (to become English teachers) to being a teacher trainer. I did my undergraduate study in ELT at a state university in Vietnam. My Master's degree in TESOL was obtained in 2004 from an Australian university after I worked as a high school teacher for about two years. After my graduation, besides providing private English courses for office employees, I worked as a lecturer for some universities in Ho Chi Minh City and a teacher trainer at South East Asia Ministers of Education Organization, Regional Training Center (SEAMEO RETRAC), Vietnam. At the universities, I mainly taught Vietnamese pre-service English teachers while my tasks at SEAMEO RETRAC were to train Vietnamese teachers of English in the Vietnam's National Foreign Language 2020 Project (Project 2020) and Vietnamese university lecturers awarded with the government scholarships for their overseas studies. In 2011, I started my PhD study in English Language Studies in Thailand and finished it in 2014. During that time, I taught both Thai university students and university staff, and during my three-month summer break I conducted training courses for provincial teachers of English in the Project 2020 in Vietnam. Two months before the completion of my PhD study, I was offered a job as an English lecturer at Kalasin University, Thailand, for which I am still working. My responsibilities at this university are to teach Thai pre-service English teachers, conducting training workshops for high school English teachers and English camps for students and Kalasin officials. Up to now, I have one text book, two book chapters and 28 research articles, and 21 of which were published in Scopus and ISI-indexed journals. Besides, I also served as a reviewer and an editor for peerreviewed international journals, a committee member of $\mathrm{MA}$ and $\mathrm{PhD}$ graduate thesis 
defenses, a supervisor for TESOL Master's and Applied Linguistics PhD candidates in Iran, Thailand and Vietnam.

\subsection{How I have grown in my research life}

Working in different educational settings and with students of different cultural backgrounds has shifted my research foci as well as my research approaches. So far, I have shifted my research interests three times in response to the practical issues at my teaching contexts. My first paper (Nguyen, 2012) shared what I did to motivate my students in IELTS and TOELF test-preparation writing courses in Vietnam. This study was conducted as I observed that teachers were not pleased when being assigned to teach these academic writing courses. Furthermore, from my informal conversations with some of them, it was known that teaching these courses were boring as their students were unmotivated. To confirm my observation and to share some motivating activities to teach TOEFL iBT and IELTS writing courses with them, I employed an action research within the interpretative paradigm. In particular, I first developed six open-ended questions for the teachers to learn about their writing activities and class atmosphere. Then a range of activities to create a positive atmosphere in my writing classes and another set of open-ended questions for students to evaluate the effectiveness of my teaching activities and techniques were developed. Vietnamese students' culturally-based learning styles and expectations were also taken into consideration in developing the activities. Besides interactive activities, regular and timely feedback, visual aids and appropriate supplementary sources, the findings showed that the use of a teaching diary had the most motivating outcomes. These findings revealed the importance of understanding the socially-expected role of teachers in Vietnam in developing relevant activities to assist Vietnamese students. In fact, in Vietnam, teachers should act as the students' confidant in class and know their students' strengths and weaknesses in order to instruct them appropriately on how to improve their writing. By doing this on a regular basis, the teachers' role in class is similar to that of parents at home in Vietnam, who are always beside their children with advice and instructions. Though my findings received positive comments from my colleagues and the board of directors at that workplace, weaknesses existed because this was my first research. No interviews with the participants and no observation of less motivated writing teachers' classes were conducted to provide more insights about students' difficulties, attitudes, beliefs and expectations for these TOEFL iBT and IELTS test-preparation writing courses. With 
this further qualitative information, my data would have been enriched and the findings were uplifted.

My next research project was my PhD work which studied the move-step structures and the types and functions of in-text citations and reporting verbs used in each chapter of the whole TESOL M.A. theses written by Vietnamese students (Nguyen, 2014). This topic was selected for various reasons. First, it was due to the reported problems that native-English and multilingual writers have in composing this genre, and this was not an exception for Vietnamese graduates. Moreover, citations are reported to (1) perform different rhetorical functions in different thesis chapters (Chen \& Kuo, 2012), (2) have complex communicative purposes with syntactic, semantic and pragmatic variations (White, 2004) and (3) vary between different disciplines, genres and even cultures (Harwood, 2009; Soler-Monreal \& Gil-Salom, 2012). Additionally, the use of reporting verbs was reported to be challenging due to the complex interaction between lexical choices with denotative and evaluative functions and their rhetorical goals. Despite these challenges, referring to other works has not been formally taught to TESOL M.A. students in Vietnam, and how citation is used in their writing is a secondary concern of their supervisors as they know that in the defense session, citation is either not judged by the thesis examiners, or not given due weightage. With such challenges, this inquiry was conducted to explore how Vietnamese M.A students composed their theses and used citations and reporting verbs in their theses. To find out the answer, I employed the Pragmatic paradigm which allowed me to probe deeper insights into the various aspects of these Vietnamese writers' choices in constructing the theses and using citations and reporting verbs.

There were two phases in this study: the qualitative (interview) data (phase 2) were collected after the textual analysis (phase 1) to help explain or elaborate on the quantitative results found in phase 1. In particular, the move-step structures of each chapter in TESOL M.A. theses and the use of citation types and functions and reporting verbs to achieve the chapters' rhetorical purposes were analyzed with the help of Antconc software. In the $2^{\text {nd }}$ phase, the results of the text analysis were triangulated with the interview data with actual thesis writers and their thesis supervisors. The qualitative method (semistructured interview) was selected to have a deeper understanding of the practice of thesis writing and the employment of citations by these Vietnamese writers. As reported in the literature, such research approaches would allow researchers to probe where further clarifications or explanations regarding various aspects of the writing process were needed (Biber, Connor, \& Upton, 2007). Moreover, this discourse-based interview displays the strengths of interview-based approach in studying citation functions and 
evaluative functions of reporting verbs (Harwood, 2009). In fact, citation functions and the evaluative aspects of reporting verbs cannot always be straightforwardly read off by text analysts, so interviews with actual writers can sidestep the major problem with relying on the surrounding text and researchers' specialized knowledge. Thus, the employment of more than one research methods that Pragmatic paradigm holds in my study was to obtain the appropriate data (quantitatively and qualitatively) from the texts and people involved for studying the practice of writing this genre at the Vietnamese TESOL context.

My last and current research topics have centered around the practical issues that my Thai pre-service teachers have faced in their learning English writing and how to teach EFL writing. It took me almost two years to locate and pilot the topics of significance to these students in their culturally-based learning environment as reported in the literature. In fact, my students' writing ability was of particular concern as they were not taught four macro skills (listening, speaking, reading and writing) until their third year of study although these students were English-majors (Nguyen, 2017, 2018a, 2018b, 2019b). What English-major students at this university study in their first two years are general subjects in Thai language. Furthermore, the absence of English in the area where these students are from and where the university is located tends to lead the students to great difficulties in English writing or even in learning other skills. From my observations, these Thai students had difficulties in organizing their essays in English, and they often planned their essays in Thai language and then used Google to translate them into English without noticing the different nature of each language (Nguyen, 2018b). To confirm my observations, the open-ended questionnaire which aimed to learn about these students' writing strategies, difficulties, topics of interest, and expectations in studying English writing was administered at the end of the term. Additionally, to verify whether or not the similar batch of students at this university shared the similar strategies, difficulties and expectations in learning essay writing, a year later another group of the fourth-year English-major students were also surveyed, using the same questionnaire. Their responses showed that their strategies, difficulties, topics of interest and expectations were almost identical. With the consideration of what was found from the questionnaire from two successive groups of students, I developed genre-based lessons to teach them essay writing. Finally, the 5-point Likert survey was administered at the end of the semester to evaluate the effectiveness of this modified genre-based instruction. Besides a thorough interpretation of the data collected from the questionnaire, students' essays, their scores for each essay and the survey on the effectiveness of the genre-based teaching approach, I also conducted semi-structured 
interviews with a focus group of fifteen students to triangulate with the findings from the survey and the text analysis of the essays. Although this study was an action research within a pragmatic paradigm, various research methods were employed to understand and interpret my fourth-year students' difficulties and expectations in studying English writing and their evaluations of the effectiveness of my modified genre-based instruction with the consideration of their culturally-based learning styles. Among the six mixed methods designs by Creswell (2012), this study fits into the Exploratory Sequential Mixed Methods Design (or a two-phase design) category. It was because the qualitative data (questionnaire) was collected first to explore the research problem (their English writing difficulties) (phase I). After analyzing the qualitative data, an experiment (developing and teaching genre-based lessons) (phase II) was developed and conducted and then examined in a quantitative manner (text analysis, students' scores and a 5-point Likert survey) to define and measure the findings (the effectiveness of the modified genrebased lessons in assisting these Thai students' English writing).

Another research topic formulated from the students at my current work place is applying peer feedback strategies to revising and editing their writing (Nguyen, 2017, 2019b). As reported in the literature of English learning and teaching in Thailand, English writing is not systematically taught as a subject, most writing programs are still taught using the grammar-translation approach (Chamcharatsri, 2010; McDonough, 2004), and the formative tests in most writing programs include sentence completion, reordering sentences, reordering words and error correction. Students thus have very few actual opportunities to represent their ideas and knowledge through the written mode. Moreover, in Thai educational contexts, students have not been required to engage actively in class activities; therefore, cooperative work often leads to Thai students' resistance and confusion (Kongpetch, 2006; McDonough, 2004). Furthermore, Thai students preferred teachers' feedback (Srichanyachon, 2012) and refused to give their drafts to peers for comments (Chamcharatsri, 2010). Such practices in writing classrooms in Thailand are likely to make it difficult for Thai students to develop their writing abilities and cause an overreliance on the teacher for all kinds of corrections and guidance. To assist my Thai students to become self-regulated writers, I reviewed the literature on written corrective feedback and found Rollinson's (2005), and his suggestions were incorporated into my paragraph-writing curriculum. To understand these students' attitudes towards this new learning activity, a five-point Likert scale survey and a focus-group interview were conducted. Furthermore, to learn about the usefulness and the effectiveness of this modified curriculum with the students whose learning styles are culturally-based, the employment of provided feedback in the revised drafts, peer and teacher comments 
(both valid and invalid ones), and how they incorporated the feedback provided by their peers and teacher (correct and incorrect revisions) were recorded. Their writing scores were also examined to evaluate their overall improvement. Besides these, I also explored how this feedback model helped reduce these Thai university students' writing errors and how they responded to each error for the improvement of their writing accuracy by employing a survey and a focus group semi-structured interview (Nguyen, 2018a). In addition to confirming the effectiveness of this feedback model in assisting Thai students with their reported learning cultures, my study also showed their evaluations of each error difficulty level, their revision strategies and the frequencies of their accurate corrections. To help my Thai students to become independent writers, I employed the Embedded Research Design (Creswell, 2012), which aimed to collect quantitative and qualitative data sequentially to address different questions derived from the primary research question (Is the combined feedback model successful in the educational setting in Thailand?). In fact, to answer the primary research question, the quantitative data (5-point Liker scale survey on their attitudes towards the curriculum, their writing scores and frequencies of the feedback provision and incorporations) were collected, followed by qualitative data on how these students responded to each error, what strategies they employed to fix each error and their evaluation of the revisions through my observations and notes and interviews with the students. In this study, the experiment (applying the revised feedback curriculum) is the primary research method and the qualitative approach is the complementary method used to compensate for the methodological deficiencies of the experiment.

One more similar research design to assist my Thai students is the modification of my feedback strategies in an essay-writing class (Nguyen, 2019a). Feedback was given with a consideration of several influential factors (students' learning experiences, English proficiency levels, feedback preferences and classroom settings). Data were first collected in terms of feedback forms, locations, types and purposes. Additionally, to learn about students' opinions on the effectiveness of these feedback strategies, a survey with the whole class and a focus-group interview with students were also conducted at the end of the course. Furthermore, the levels of the students' reactions (no, minimum or substantial) to the teacher feedback, the effects of their revisions (improved, mixed or negative) and their revision strategies (addition, deletion, substitution, permutation and distribution and consolidation) were also examined.

My last research topic at the current workplace is concerned with how to effectively teach English writing to Thai pre-service teachers (Nguyen, 2019 In Press). The English language education program for prospective English teachers in Thailand has been 
reported to have several fundamental problems, such as absence of theoretical and pedagogical knowledge and critical thinking skills, rote-memorization teaching styles, teacher-centeredness and high levels of under-prepared teachers and students' low levels of language proficiency. Being informed with these issues, I employed the reflective teaching approach to assist 48 Thai pre-service English teachers to learn how to teach English writing. In order to learn to what extent my reflective teaching approach assisted this group of Thai students in learning to teach English writing, I employed the survey and my notes taken during the course. Furthermore, which areas of my instruction needed revisions or improvement was identified and triangulated by the educator (me) and students' (teaching groups and their peers) evaluations on the students' micro-teaching performances. The students' reflections on their teaching strengths and weaknesses and their plans for reconstructing their teaching were also examined. The focus-group semi-structured interview was also conducted at the end of the course to clarify the findings from the survey and evaluations. With the informed knowledge of Thai students' culturally-based learning styles, in this study I became a reflective practitioner in my own classroom to find out what was appropriate to develop my Thai students' pedagogical and content knowledge in teaching EFL writing. Doing this, I was following the Interpretive paradigm to interact with the participants (my students) and to gain enhanced understanding of their needs and expectations so that I could adjust my teaching approach accordingly.

In general, the Interpretive and Pragmatic paradigms were mainly employed to address my research problems because these approaches enabled me to gain better understanding of my students and their practical problems and then to adjust my curriculum in order to appropriately assist them with their cultural-based learning styles. In fact, as an English teacher dealing with the intricacies of university life, I prefer a heuristic or pragmatic approach as it is not restricted by ontological and epistemological issues when deciding on how to address a variety of different research questions. Furthermore, this approach tends to be more practical as a form of the investigation on teacher-student interaction which manifests itself in multiple ways. This also shows that no research paradigm is superior, but each has a specific purpose in providing a distinct means of producing unique knowledge in a specific context. Although the findings of my studies may not be generalized to other contexts, they provide teacher-educators, both in Thailand and Vietnam, or in other educational settings with similar teaching and learning cultures, insights to facilitate meaningful learning for their students. This practice in research would bridge the perceived gap between research knowledge and practice as educators are the researchers in their own classrooms. 


\section{Future Directions}

The increasing changes in research methodology in the social sciences bring new ways of approaching research problems to better meet the emerging educational needs of the rapidly globalizing societies. With the complexity of current educational issues, it is necessary for teacher-educators to look for multifaceted research designs to not only provide informative evidence-based research outcomes and socially-constructed knowledge but also search for answers to their practical problems. As reported in a recent study (Crawford \& Tan, 2019), there is an increasing trend in using multiparadigmatic research designs, and this implies that teacher-educators are increasingly aware of the flexibility offered by this research approach, and how it can be used to investigate complex issues within their localized contexts. In fact, in the current era where accountability and evidenced-based practice are essential, educators and researchers should take direct actions to seek the answers to their problems which are related to students' emerging needs and their teaching practices in a principled effort. This involves their informed knowledge of not only the educational settings but also research paradigms.

Besides the multi-faceted research designs, teachers should be the researchers in their own classroom. As argued by Anwaruddin (2019, p. 10), "teaching is not a purely technical activity where the end goal is pre-determined and achieved by applying precise methods"; teachers should be a questioner. (Anwaruddin, 2019, p. 10). For pedagogies to be effective, teachers are expected to question the impact of their teaching on the students because teaching strategies work differently in different contexts for different students (Alexakos, 2015; Miller \& Shinas, 2019). In fact, each classroom contains its complexities and uncertainties within its own local settings, what decisions teachers make requires their understanding and contextually-responsive modifications of their research-based knowledge. Therefore, classroom teachers should systematically inquire into their classroom life to better understand themselves, their students and their own practices, and then use that knowledge to continually reform, refine and change their practices and build greater practical knowledge for themselves. With their insider knowledge from conducting their own inquiry, teacher researchers can address the problems they encounter in their classrooms and schools that outsiders or academic researchers may not perceive or deem relevant.

Also, it is suggested that teachers who have been involved in research will grow considerably in their professional development (Alexakos, 2015; Anwaruddin, 2019). It is true that when doing research teachers are open to new ideas and possibilities 
to what strategies might work for their students with their own contextual needs that the vast existing literature cannot provide. Their epistemological openness is hence crucial for the practice of teaching, which is inseparable from teachers' practical wisdom and ethical judgments based on different kinds of knowledge. In fact, as confirmed by Alexakos (2015, p. 41), "researching our practice is an opportunity to learn". Different from positivistic-type research which is conducted to find laws or law-like generalizations, teacher research is about learning, changing, developing and implementing practices that assist learning and teaching of the researcher and all involved. Such research gives teacher researchers more authentic, useful and valuable knowledge than the research knowledge generated by academic researchers. As reported in the literature, the knowledge produced by academic researchers is characterized by its generalisability and contextual independence while the knowledge classroom teachers need is the one with its practicality, concreteness and contextual richness. Teachers' conducting their own classroom research thus helps bridge the so-called research-practice gap.

\section{Conclusion}

In conclusion, changes in methodology for research in social sciences to which ELT belongs bring new approaches to address research problems. With newer research paradigms, teacher-researchers are empowered to address problems related to new policies and practices that better meet the emerging and challenging educational needs of their students in the digital era. In fact, with their informed knowledge of the research paradigms, researchers can design their research by combining different methods with quality standards drawn from two or more research paradigms. By drawing on multiple paradigms, educators can make a major contribution to regulating language education curricula and resolving practical problems in their own teaching settings.

However, there is no single best research paradigm for all research, but each has a specific purpose in providing a distinct means of producing unique knowledge in a particular setting. My reflections also suggest that the choice of a research paradigm relies on its appropriateness to a research problem and the researcher's personal experience and training. In fact, I personally believe that each research project would have a different theoretical perspective and hence a different research paradigm. It is probably neither strictly a top down or bottom up approach, but researchers probably go back and forth till they find the right fit. 


\section{Acknowledgement}

I would like to extend my deep gratitude to Ifzal Syed for his insightful discussion which made it easy for me to complete this article.

\section{References}

[1] Alexakos, K. (2015). Being a teacher I researcher: A primer on doing authentic inquiry research on teaching and learning. Rotterdam, The Netherlands: Sense.

[2] Anwaruddin, S. M. (2019). Knowledge mobilization in TESOL: Connecting research and practice. Leiden: Brill.

[3] Biber, D., Connor, U., \& Upton, T. (2007). Discourse on the move: Using corpus analysis to describe discourse structure. Amsterdam: John Benjamins.

[4] Chalmers, D., Manley, D., \& Wasserman, R. (2005). Metametaphysics: New essays on the foundations of ontology. New York: Oxford University Press.

[5] Chamcharatsri, P. B. (2010). On teaching writing in Thailand. Writing on the Edge, 21(1), 18-26.

[6] Chen, T.-Y., \& Kuo, C.-H. (2012). A genre-based analysis of the information structure of master's theses in applied linguistics. The Asian ESP Journal, 8(1), 24-52.

[7] Crawford, R., \& Tan, H. (2019). Responding to evidence-based practice: An examination of mixed methods research in teacher education. The Australian Educational Researcher, 1-23. doi:https://doi.org/10.1007/s13384-019-00310-w

[8] Creswell, J. W. (2007). Qualitative inquiry and research design: Choosing among five approaches (2nd ed.). Thousand Oaks, CA: Sage Publications.

[9] Creswell, J. W. (2008). Educational research: Planning, conducting and evaluating quantitative and qualitative research (3rd ed.). Upper Saddle River, NJ: Pearson Prentice Hall.

[10] Creswell, J. W. (2012). Educational research: Planning, conducting, and evaluating quantitative and qualitative research (4th ed.). Boston, MA: Pearson.

[11] Creswell, J. W., \& Plano, C. V. L. (2011). Designing and conducting mixed methods research (2nd ed.). Thousand Oaks, CA: Sage.

[12] Denzin, N. K., \& Lincoln, Y. S. (2000). Handbook of qualitative research. London: Sage.

[13] Fadhel, K. (2002). Positivist and hermeneutic paradigm: A critical evaluation under their structure of scientific practice. The Sos/and Journal, 21-28. 
[14] Ghiara, V. (2019). Disambiguating the role of paradigms in mixed methods research. Journal of Mixed Methods Research, 1-15. doi:https://doi.org/10.1177/ 1558689818819928

[15] Guba, E. G., \& Lincoln, Y. (2005). Paradigmatic controversies, contradictions \& emerging confluences. In The Sage handbook of qualitative research (3rd ed.). California: Sage.

[16] Harwood, N. (2009). An interview-based study of the functions of citations in academic writing across two disciplines. Journal of Pragmatics, 41(3), 497-518. doi:http://dx.doi.org/10.1016/j.pragma.2008.06.001

[17] Johnson, R. B. (2011). Do we need paradigms? A mixed methods perspective. MidWestern Educational Researcher, 24(2), 31-40.

[18] Kivunja, C., \& Kuyini, A. B. (2017). Understanding and applying research paradigms in educational contexts. International Journal of Higher Education, 6(5), 26-41. doi:doi:10.5430/ijhe.v6n5p26

[19] Kongpetch, S. (2006). Using a genre-based approach to teach writing to Thai students: A case study. Prospect, 21(2), 3-33.

[20] Kuhn, T. S. (1962). The structure of scientific revolutions (1st ed.). Chicago: University of Chicago Press.

[21] Lincoln, Y. S., \& Guba, E. G. (1985). Naturalistic inquiry. Thousand Oaks: Sage.

[22] Mackenzie, N., \& Knipe, S. (2006). Research dilemmas: paradigms, methods and methodology. Issues In Educational Research, 16, 1-15.

[23] Maxwell, J. A. (2016). Expanding the history and range of mixed methods research. Journal of Mixed Methods Research, 10(1), 12-27. doi:10.1177/1558689815571132

[24] McDonough, K. (2004). Learner-learner interaction during pair and small group activities in a Thai EFL context. System, 32, 207-224.

[25] Mertens, D. M. (2015). Research and evaluation in education and psychology (4th ed.). Los Angeles: Sage.

[26] Miller, M. S., \& Shinas, V. H. (2019). Inquiring about inquiry: A research journey. Journal of Practitioner Research, 4(1), 1-24. doi:https://doi.org/10.5038/2379-9951.4.1.1093

[27] Morgan, D. L. (2007). Paradigms lost and pragmatism regained: Methodological Implications of combining qualitative and Quantitative methods. Journal of Mixed Methods Research, 1(1), 48-76.

[28] Morgan, D. L. (2014). Pragmatism as a paradigm for social research. Qualitative Inquiry, 20(8), 1045-1053. doi:10.1177/1077800413513733 
[29] Nguyen, T. T. L. (2012). Motivating activities in test preparation writing classes: A case study in Vietnam. Language Education in Asia, 3(1), 71-84. doi:10.5746/LEiA/12/V3/I1/A07/Loan

[30] Nguyen, T. T. L. (2014). Move-step structures and citation practice in English TESOL master's theses by Vietnamese students. (Ph.D dissertation), Suranaree University of Technology, Thailand, Nakhon Ratchasima.

[31] Nguyen, T. T. L. (2017). A case study of combined peer-teacher feedback on paragraph writing at a university in Thailand. Indonesian Journal of Applied Linguistics, 7(2), 15-24.

[32] Nguyen, T. T. L. (2018a). The effect of combined peer-teacher feedback on Thai students' writing accuracy. Iranian Journal of Language Teaching Research, 6(2), 117-132.

[33] Nguyen, T. T. L. (2018b). Reflections on modified genre-based instructions to teach essay writing to Thai university students The Asian EFL Journal, 20(9.1), 148-174.

[34] Nguyen, T. T. L. (2019a). A case study of teacher feedback on Thai university students' essay writing. GEMA Online Journal of Language Studies, 19(2), 121-138. doi:http: //doi.org/10.17576/gema-2019-1902-08

[35] Nguyen, T. T. L. (2019b). Implementing peer-feedback in paragraph-writing classes at a Thai university. In S. M. Anwaruddin (Ed.), Knowledge mobilization in TESOL: Connecting research and practice (1 ed., pp. 30-42). Leiden, The Netherlands: Brill.

[36] Nguyen, T. T. L. (2019 In Press). Reflective teaching in an EFL writing instruction course for Thai pre-service teachers. The Journal of Asia TEFL, 16(2).

[37] Patton, M. Q. (2002). Qualitative research and evaluation methods (3rd ed.). Thousand Oaks: Sage.

[38] Richards, K. (2009). Trends in qualitative research in language teaching since 2000. Language Teaching, 42(2), 147-180.

[39] Rollinson, P. (2005). Using peer feedback in the ESL writing class. ELT Journal, 59(1), 23-30. doi:10.1093/elt/cci003

[40] Schwandt, T. A. (2001). Dictionary of qualitative inquiry (2nd ed.). Thousand Oaks: Sage.

[41] Scotland, J. (2012). Exploring the philosophical underpinnings of research: Relating ontology and epistemology to the methodology and methods of the scientific, interpretive, and critical research paradigms. English Language Teaching, 5(9), 916. doi:https://doi.org/10.5539/elt.v5n9p9

[42] Scott, D., \& Usher, R. (2004). Researching education: Data, methods, and theory in educational enquiry. New York: Continuum. 
[43] Searle, J. R. (2015). Seeing Things as they Are: A theory of perception. Oxford: Oxford University Press.

[44] Soler-Monreal, C., \& Gil-Salom, L. (2012). A cross-language study on citation practice in Ph.D. theses. International Journal of English Studies, 11(2), 53-75.

[45] Srichanyachon, N. (2012). An investigation of university EFL students' attitudes toward peer and teacher feedback. Educational Research and Reviews, 7(26), 558562.

[46] Taylor, P. C., \& Medina, M. N. D. (2013). Educational research paradigms: From positivism to multiparadigmatic. Journal for Meaning-Centered Education, 1, 1-16.

[47] White, H. D. (2004). Citation analysis and discourse analysis revisited. Applied Linguistics, 25(1), 89-116.

[48] Willis, J. W. (2007). Foundations of qualitative research: Interpretive and critical approaches. Thousand Oaks, CA: Sage. 